\title{
Integration of Biological and Chemical Controls for Rhizoctonia Aerial Blight and Root Rot of Rosemary
}

\author{
K. E. Conway, Department of Plant Pathology, and N. E. Maness and J. E. Motes, Department of Horticulture and \\ Landscape Architecture, Oklahoma State University, Stillwater 74078-3032
}

\begin{abstract}
Conway, K. E., Maness, N. E., and Motes, J. E. 1997. Integration of biological and chemical controls for Rhizoctonia aerial blight and root rot of rosemary. Plant Dis. 81:795-798.

Aerial blight, caused by Rhizoctonia solani AG-4, was identified as a major disease of greenhouse mist-produced rosemary cuttings. An isolate of the biocontrol fungus Laetisaria arvalis, selected for tolerance to the experimental fungicide CGA 173506, was used as an amendment to potting soil. Combined treatment of rosemary with $L$. arvalis and a foliar spray of the fungicide at one-half the recommended rate reduced disease more than treatment with either the fungus or fungicide alone. Similar synergism was not observed for combinations of Trichoderma harzianum as a soil amendment and a foliar spray of the fungicide iprodione applied at the labeled rate.
\end{abstract}

Additional keywords: ectotrophic growth, synergy

Rosemary (Rosemarinus officinalis L.) seed viability is low, and those that germinate produce a wide variety of plant types (7). To maintain uniformity among rosemary plants, asexual propagation is necessary; however, rosemary is difficult to propagate (11). Generally, there are two major disease problems for rosemary cuttings: root rot and powdery mildew (9). Rhizoctonia solani Kühn, a soilborne fungus, drastically decreases the survival rate of rooted cuttings (5). $R$. solani survives in infected roots, which can become embedded in the walls of Speedling Styrofoam100A flats (Speedling, Inc., Sun City, FL), commonly used for propagation (17). These infected roots are resistant to sterilization procedures such as sodium hypochlorite washes and can reinfest the potting mixes during propagation. Spread of the pathogen is extremely rapid once the root and main stem are infected. The fungus moves upward along the stem, causing an aerial blight in which the fungus can rapidly infect an entire flat in just a few days by growing ectotrophically from plant to plant.

Our objective was to combine biological and chemical control into an integrated strategy to reduce losses to disease caused by $R$. solani in rosemary. Biological control agents and rates used were derived from previous research (3-6). Fungicides were selected from previous research (13)

Corresponding author: K. E. Conway

E-mail: kenncon@osuunx.ucc.okstate.edu

Accepted for publication 10 April 1997.

Publication no. D-1997-0521-05R

(C) 1997 The American Phytopathological Society and for their efficacy in controlling diseases caused by $R$. solani. In addition, we investigated the inoculum concentrationdisease relationship between our formulation of $R$. solani and rosemary cuttings and the effect of inoculum placement on disease development.

\section{MATERIALS AND METHODS}

Rosemary propagation. Cuttings taken from greenhouse-grown source plants were 9 to $18 \mathrm{~cm}$ long with the lower half of the foliage removed (2). Pathogen-free plants were used as source plants for our experiments. Cuttings from each source plant were assayed on a modified Rhizoctoniaselective medium (8). Each liter of modified medium contained $20 \mathrm{~g}$ of agar, $5 \mathrm{~g}$ of inulin, $6 \mathrm{mg}$ (a.i.) of benomyl, $21 \mathrm{mg}$ of copper sulfate, and $70 \mathrm{mg}$ of chlorotetracycline HCL.

Previous research projects showed that $0.08 \%$ indole butyric acid powder-talc dip gave the best rooting (18). Cuttings were rooted on mist benches in a greenhouse in May and July 1992. Fafard potting soil mix (Conrad Fafard, Inc., Aquawam, MA) was placed into plastic six-pack rooting containers, and one hormone-treated rosemary seedling was placed into each cell of the six-pack.

Characterization and inoculum production of $\boldsymbol{R}$. solani. $R$. solani OK-367 was isolated from diseased rosemary cuttings. The severity and prevalence of the disease caused by this pathogen, reported from local greenhouse production facilities, and the lack of control by labeled fungicides during 1991 were the major reasons for initiating this research.

The number of nuclei per cell of $R$. solani OK-367 was determined with flores- cence microscopy and acridine orange stain. The anastomosis group of OK-367 was determined on agar-coated slides (10), with cultures originally from Ogoshi (19) provided by R. J. Cook.

Inoculum of $R$. solani was prepared by a method developed by M. G. Boosalis (personal communication). A $33 \times 23 \mathrm{~cm}$ cake pan was one-third filled with vermiculite, covered with aluminum foil, and autoclaved $\left(121^{\circ} \mathrm{C}, 1.05 \mathrm{~kg} / \mathrm{cm}^{2}, 15 \mathrm{~min}\right)$. In a separate container, 400 to $500 \mathrm{ml}$ of cornmeal was covered and autoclaved three times. The autoclaved cornmeal and vermiculite was mixed in the cake pan, and $550 \mathrm{ml}$ of sterile tap water was added. Agar and mycelium in three to four petri dishes of actively growing $R$. solani was cut into cubes and added to each pan, mixed thoroughly, and incubated 2 to 3 weeks at room temperature. The mixture was loosened from the pans, spread on a tray, covered with cheesecloth, and allowed to dry overnight at room temperature. The mixture was further separated using a rolling pin. For sclerotial development, wheat bran was substituted for cornmeal. The mixture was placed in paper bags and stored at room temperature. The mixture was sieved through nested 500and $250-\mu \mathrm{m}$-aperture screens for greater particle uniformity.

Inoculum concentration-disease incidence relationship. The objective of these experiments was to determine a reasonable amount of $R$. solani inoculum to add to potting soil to evaluate the efficacy of biological and chemical controls. Inoculum of $R$. solani was prepared as described and mixed into potting media with a twin-shell blender (Patterson-Kelly Co., East Stroudsberg, PA) on a percentage by weight basis: $0.01,0.1$, and $1.0 \%$.

Origin of isolates and selection for fungicide tolerance. Isolates of Trichoderma harzianum Rifai OK-110 isolated from soil in Stillwater, Oklahoma, and Laetisaria arvalis Burdsall OK-206 acquired from the Forest Products Laboratory, Madison, Wisconsin, ATCC 62715, were plated onto potato dextrose agar (PDA) amended with a 10-fold dilution series of either of the fungicides iprodione or CGA 173506. When growth of the colony was observed at the greatest fungicide concentration, hyphal tip transfers were made to nonamended PDA. After 7 days of growth, the colony was transferred to PDA amended with the greatest fungicide con- 
centration, $1,000 \mu \mathrm{g} / \mathrm{ml}$, to verify that reversion had not occurred.

Production of T. harzianum inoculum. T. harzianum was prepared as a molassesbran-fermentation product (20) in a HiDensity Lab-Line Fermentor System (No. 29500, LabLine Instruments, Inc., Melrose Park, IL). After 1 week of growth, mycelial fragments and conidia were collected on a 500- $\mu$ m-aperture sieve, spread on waxed paper, dried, and ground to a fine powder in a Glen Mills grinder (Glen Mills Co., Maywood, NJ). T. harzianum was added at a rate of $5.0 \mathrm{~g}$ of fermentation product $/ \mathrm{kg}$ of potting medium (equivalent to $10^{6} \mathrm{CFU} / \mathrm{g}$ ).

L. arvalis was grown in potato dextrose broth, and sclerotia were separated from the mycelium by washing through nested sieves (500-, 250-, and 180- $\mu \mathrm{m}$ apertures). Sclerotia were collected on the $250-\mu \mathrm{m}$ aperture sieve and placed on waxed paper to dry. $L$. arvalis was applied at the rate of $5.0 \mathrm{~g}$ of dried sclerotia/ $\mathrm{kg}$ of potting soil.

Inoculum concentration experimental units were arranged in Latin-squares on greenhouse benches. Ten rosemary cuttings were planted into individual planting holes (one cutting per hole) of a propagation tray containing one of the inoculum concentrations. Each concentration was replicated eight times. Cuttings were evaluated weekly for disease incidence (dead plants and brown discoloration or lesions on the leaves). At 4 weeks, cuttings were removed and roots were evaluated for discoloration, dried, and weighed. Numbers of infected plants in each treatment were subjected to analysis of variance (ANOVA), and means were separated by a Student-Newman-Keuls mean separation test $(P=0.05)$. The experiment was conducted twice in a greenhouse in May and June 1992.

Disease control studies: Inoculum methods. In order to determine the best method of inoculating rosemary cuttings with $R$. solani to initiate disease, two methods for pathogen inoculation were evaluated to simulate both aerial and soil spread of the disease. Fafard potting soil mix was placed into plastic six-pack rooting containers, and one hormone-treated rosemary seedling was placed into each cell. Inoculation with $R$. solani was accomplished by two different techniques: to simulate aerial blight, plants in individual six-packs were misted with water and dusted with $0.1 \mathrm{~g}$ of the $0.1 \% R$. solani mix; to simulate the soil spread of the pathogen, a 1.0-cm-diameter disk removed from an actively growing culture of $R$. solani was placed on the surface of potting soil in one of the end cells of the six-pack. Biocontrol agents were added to Fafard mix in the twin-shell blender to achieve propagule densities described in the section on biological control agents. Fungicides were applied at label and recommended rates to runoff either before (protectant spray) or after (therapeutic spray) inoculation with the pathogen.

Treatments were replicated eight times, with each treatment confined to one sixpack containing six rosemary cuttings, and were randomly arranged in a complete block design inside a mist chamber. Controls received no fungicide application, soil amendment, or pathogen inoculation. Numbers of dead plants were recorded daily for 2 weeks. Surviving plants were removed and primary roots were measured. Secondary roots were trimmed from the primary root and weighed (fresh weight). An ANOVA was conducted on the numbers of dead plants and the length and weight of the roots. When the $F$ test was significant, means were separated using a Student-Newman-Keuls test $(P=0.05)$. Each inoculation experiment was performed at least two times.

Disease control studies: Integration. The objective of this experiment was to compare the efficacy of combined biologi-

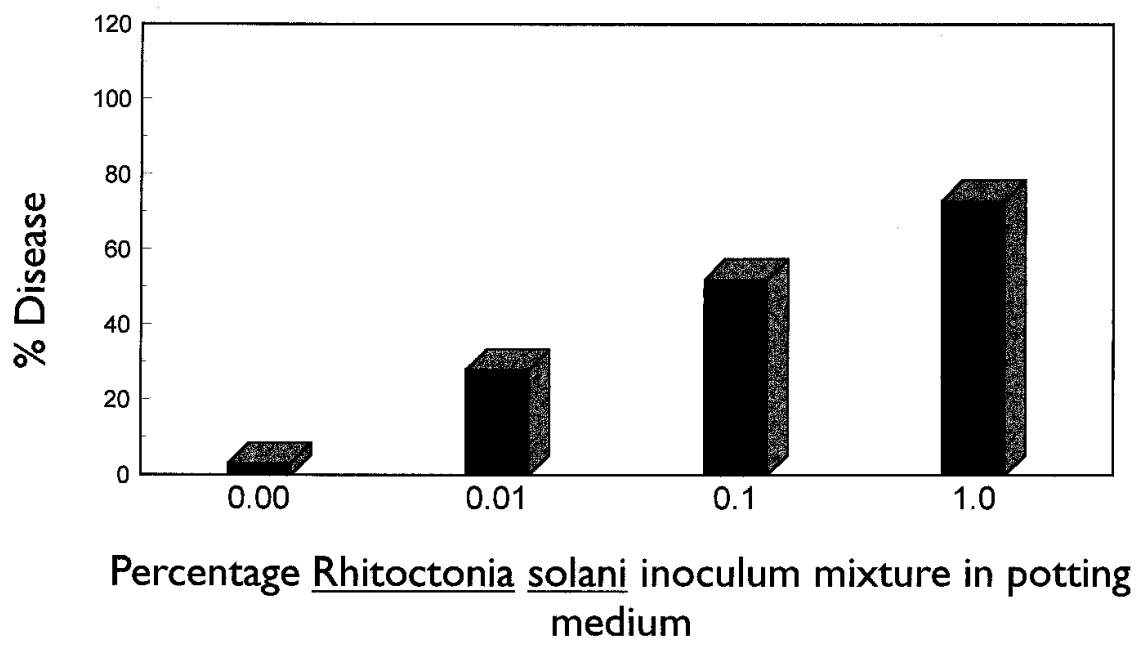

Fig. 1. Relationship between disease incidence of rosemary cuttings and the percentage of Rhizoctonia solani inoculum added (wt/wt) to the potting soil during May 1992 (4-week incubation). cal and chemical treatments with the efficacy of either used alone. In order to do this, both fungi were mixed separately into Fafard potting soil mix. Moisture content of the potting soil was adjusted to $20 \%$ (wt/vol) with water prior to the addition of biocontrol agents or pathogen. Trays were previously cleaned and disinfested with sodium hypochlorite and coated with Speedling Super-Cote (a copper-based latex paint) to inhibit $R$. solani infection from mycelium embedded in the Styrofoam of the tray. Rosemary cuttings were stuck into individual cells of a Speedling 100-A propagation tray (100 rooting cells per tray). $R$. solani inoculum was incorporated into the potting soil on a percentage by weight basis, $0.1 \%$, prior to the addition of the biocontrol agents. Each tray contained seven treatments in every other row. Treatments included the two biological agents added to the potting soil, two fungicide treatments, two combination treatments, and a control.

Fungicides and rates evaluated were CGA 173506 (Ciba-Geigy Corp., 0.035 g/473 ml [approximately one-half recommended rate]) and iprodione (Rovral, Rhone Poulenc Inc., $1.2 \mathrm{ml} / 473 \mathrm{ml}$ [label rate]). Controls were planted into potting soil with no biological control amendment and received no fungicide. Skips were left between treatment rows to inhibit the spread of Rhizoctonia between treatments and to allow more accurate application of treatments. Fungicides were sprayed onto cuttings until runoff. Each treatment was replicated four times, and there were 10 cuttings per replication. All trays were placed inside a misting unit for 19 days, and the numbers of dead and diseased cuttings were recorded on a daily basis for 4 weeks.

\section{RESULTS}

Characterization and inoculum production of $\boldsymbol{R}$. solani. $R$. solani OK-367 was multinucleate and fused with only the AG-4 tester culture of Ogoshi (19).

Selection and inoculum production of biocontrol agents. Growth of $L$. arvalis occurred on agar medium amended with CGA 173506 at $1,000 \mu \mathrm{g} / \mathrm{ml}$. Similarly, growth of $T$. harzianum occurred on a medium amended with iprodione at 1,000 $\mu \mathrm{g} / \mathrm{ml}$. These selections were stable through several transfers to media amended at the same fungicide concentrations and were used in the integrated control studies.

Inoculum concentration-disease incidence relationship. The addition of $0.1 \%$ of the Rhizoctonia mix to Fafard potting soil produced approximately $50 \%$ disease (Fig. 1). Regression analysis for the relationship between concentration and disease was best fit by a polynomial regression equation. The development of disease recorded for the control treatment (Fig. 1) illustrates how easily disease spreads from plant to plant during aerial blight. Higher 
disease incidence was noted during periods of warmer temperature in the greenhouse (May, high of $24.5^{\circ} \mathrm{C}$ and low of $16.8^{\circ} \mathrm{C}$; July, high of $31.7^{\circ} \mathrm{C}$ and low of $21.3^{\circ} \mathrm{C}$ ) (Figs. 2 and 3).

Disease control studies: Inoculum methods. Dusting of Rhizoctonia inoculum preparation onto cuttings increased disease and reduced root weight $(P=0.05)$ compared with either the control or the plug inoculation technique (Table 1). There were no differences between the protective or therapeutic application of fungicides (Table 1). T. harzianum added as a soil amendment increased root length $(4.6 \mathrm{~cm})$ compared with the control $(3.3 \mathrm{~cm})(P=0.05)$.

Disease control studies: Integration. The combination of L. arvalis as a soil treatment with a foliar spray of the fungi- cide CGA 173506 reduced disease incidence more than either treatment alone (Figs. 2 and 3).

\section{DISCUSSION}

Web blight on rosemary was first reported in 1992 (12) and was attributed to $R$. solani AG-1. The blight occurred on landscape plantings of the cultivar Prostratus, killing up to $80 \%$ of the branches. Our isolate, OK-367, probably originated on field-grown plants used for propagation and is most severe on cuttings. Mist propagation of rosemary in the greenhouse provides ideal conditions for disease development spread: warm temperatures and high humidities.

Integration of chemical and biological controls to decrease incidence of Rhizoc-

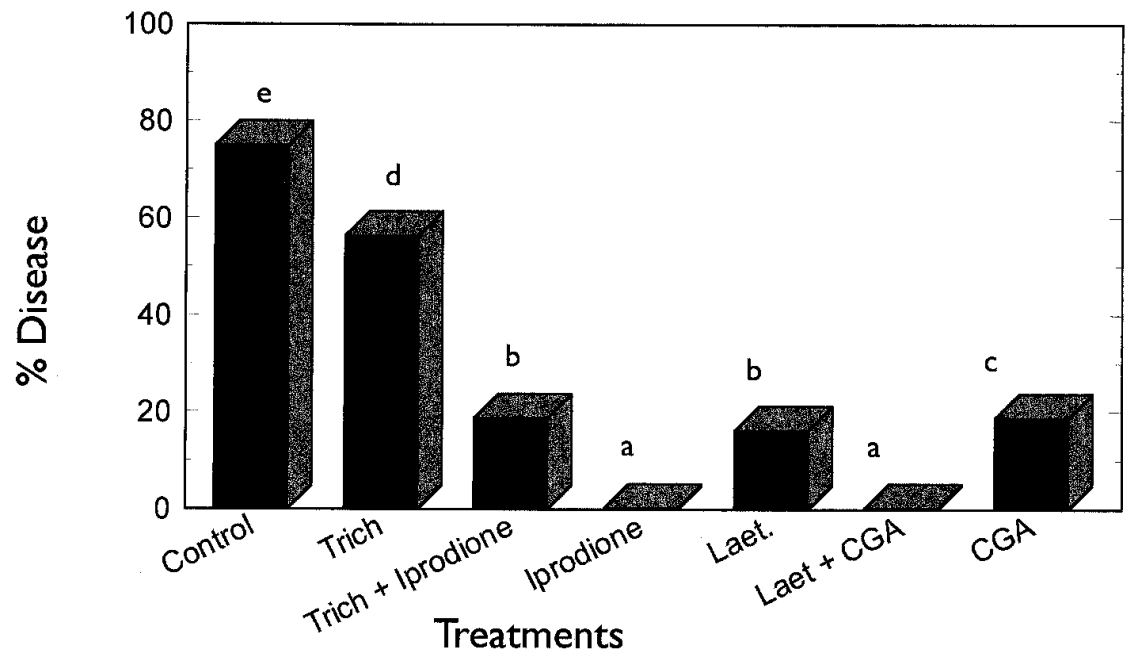

Fig. 2. Comparison of the effectiveness of chemical and biological controls, used alone or in combination, for Rhizoctonia blight of rosemary cuttings, May 1992. The density of Rhizoctonia solani inoculum mixture added to the potting soil was $0.01 \%$. Biological control agents Trichoderma harzianum (Trich), $5.0 \mathrm{~g}$ of fermentation product $/ \mathrm{kg}$ of potting soil, and Laetisaria arvalis (Laet), 5.0 $\mathrm{g}$ of dried sclerotia/kg, was added to potting soil before planting; and fungicides iprodione, 1.2 $\mathrm{ml} / 473 \mathrm{ml}$ of water, and CGA $173506,0.035 \mathrm{~g} / 473 \mathrm{ml}$ of water, were applied to cuttings until runoff. Columns with different letters are significantly different $(P=0.05)$.

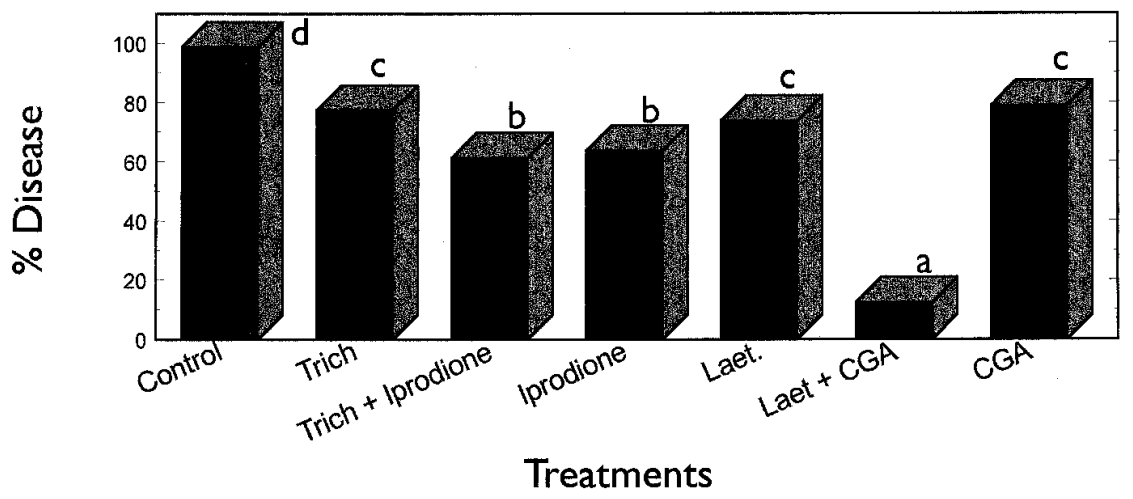

Fig. 3. Comparison of the effectiveness of chemical and biological controls, used alone or in combination, for Rhizoctonia blight of rosemary cuttings, July 1992. The density of Rhizoctonia solani inoculum mixture added to the potting soil was $0.01 \%$. Biological control agents Trichoderma harzianum (Trich), $5.0 \mathrm{~g}$ fermentation product $/ \mathrm{kg}$ of potting soil and Laetisaria arvalis (Laet), $5.0 \mathrm{~g}$ of dried sclerotia/kg was added to potting soil before planting; and fungicides iprodione, $1.2 \mathrm{ml} / 473$ $\mathrm{ml}$ of water, and CGA 173506, $0.035 \mathrm{~g} / 473 \mathrm{ml}$ of water, were applied to cuttings until runoff. Columns with different letters are significantly different $(P=0.05)$. tonia preemergence damping-off has been suggested (16); however, verification of these findings was required. The conclusion that integration of chemical and biological controls provides opportunities for enhancement and greater efficiencies in suppressing damping-off induced by $R$. solani than either technique used alone was valid. We believed that an integrated system could be more reliable than either biological or chemical control alone and could be synergistic. Foliar application of the fungicide would delay aerial blight development, but would not interfere with the biological control agent due to the selected tolerance.

Additional attempts at integration of biological agents with other disease control methods have involved combinations with cultural techniques (i.e., tillage). Success of integrating biological agents with cultural techniques to control diseases of snap bean caused by Pythium spp. and $R$. solani varied and depended on formulation and method of application of the biological agent (14). Preparations of biological control agents added in-furrow or to seed were ineffective in reducing disease when used individually or in combination with cultural or chemical methods (14). In other experiments (15), greater reduction of Rhizoctonia fruit rot was obtained with $T$. harzianum (WT-6) in conjunction with plowing than when either technique was used alone. We have shown that biological control agents selected for fungicide resistance can be integrated with those fungicides to enhance disease suppression and

Table 1. Comparison of techniques for inoculation with Rhizoctonia solani, with data pooled from two tests for all treatments for numbers of dead rosemary cuttings and root weight

\begin{tabular}{|c|c|c|}
\hline Technique $^{\mathrm{v}}$ & $\underset{(\text { no.) }}{\text { Dead plants }}$ & $\begin{array}{l}\text { Root fresh } \\
\text { weight }^{\mathrm{x}}(\mathrm{g})\end{array}$ \\
\hline Dusting, protectant ${ }^{\mathrm{y}}$ & $4.92 \mathrm{a}$ & $0.59 \mathrm{a}$ \\
\hline Dusting, therapeutic ${ }^{\mathrm{z}}$ & $4.88 \mathrm{a}$ & $0.60 \mathrm{a}$ \\
\hline Plug, protectant & $1.75 \mathrm{~b}$ & $1.17 \mathrm{~b}$ \\
\hline Plug, therapeutic & $1.25 \mathrm{~b}$ & $1.26 \mathrm{ab}$ \\
\hline Control & $0.33 \mathrm{c}$ & $1.60 \mathrm{c}$ \\
\hline
\end{tabular}

${ }^{v}$ Dusting involved misting of cuttings with water and dusting $0.1 \mathrm{~g}$ of $0.1 \% R$. solani mix onto the six cuttings in the six-pack. For the plug inoculation, a $1.0-\mathrm{cm}$ disk was removed from an actively growing culture of $R$. solani on potato dextrose agar and placed on the surface of one of the end cells of the six-pack.

${ }^{w}$ Numbers are means of six plants with eight replications. Control received no inoculum; disease incidence is naturally occurring plantto-plant spread. Means with different letters are significantly different $(P=0.05)$, StudentNewman-Keuls test.

${ }^{x}$ Weights are new secondary roots clipped from the main root and are means from six plants with eight replications.

${ }^{y}$ Fungicide sprays applied before application of $R$. solani inoculum.

${ }^{\mathrm{z}}$ Fungicides applied after application of inoculum. 
root growth. Prior research has shown that the fungicides benomyl, iprodione, and mancozeb were effective in controlling web blight in greenhouse testing on large plants (12). However, local propagators of rosemary cuttings reported little or no control using either benomyl or mancozeb (J. E. Motes, personal communication).

The difference in the success of integration with fungicides between $L$. arvalis and $T$. harzianum may be related to the higher concentration of fungicide applied in conjunction with $T$. harzianum compared with that used with $L$. arvalis, and perhaps to the difference in the mode of action and efficacy between the two. L. arvalis produces laetisaric acid (1), which is inhibitory to $R$. solani and Pythium spp. Our isolate of $T$. harzianum is a mycoparasite of $R$. solani (10) and is not known to produce fungus-inhibiting compounds.

Greater root weight of rosemary in $T$. harzianum-amended medium was similar to growth enhancement of broccoli seedlings by both biocontrol fungi in previous experiments (6).

Amendment of potting mix with either biological control agent significantly reduced the incidence of Rhizoctonia blight compared with the control treatment, which indicates that control of the soil phase of the blight by the biological agents can suppress total disease development during propagation of rosemary.

\section{ACKNOWLEDGMENTS}

We thank William Warde, Department of Statistics, Oklahoma State University, for advice, and
Kenna Mitchell, Carol Foor, Phoebe Doss, Judy Rose, and David McCraw for technical assistance. We thank Aithel McMahon (Ciba-Geigy) and Ann M. Wiese (Rhone-Poulenc), research development representatives, for donations of fungicides used in this research. This research was supported in part by Hatch funds OKLO 2117 to the first author. Some of this research represents portions of a thesis by the second author in partial fulfillment of the requirements for the M.S. degree, Oklahoma State University. The first author appreciates and gratefully acknowledges discussions with Michael G. Boosalis concerning Rhizoctonia inoculum production.

\section{LITERATURE CITED}

1. Bowers, W. S., Hoch, H. C., Evans, P. H., and Katayama, M. 1986. Thallophytic allelopathy: Isolation and identification of laetisaric acid. Science 211:105-106.

2. Clark, D. E., ed. 1988. Herbs: An Illustrated Guide. Sunset Books, Lane Publishing Co., Menlo Park, CA.

3. Conway, K. E. 1986. Use of fluid drilling gels to deliver biological control agents to soil. Plant Dis. 70:835-839.

4. Conway, K. E. 1993. Effects of formulations of Trichoderma harzianum on southern blight of apple seedlings in microplots, 1985. Biol. Cult. Tests 8:5.

5. Conway, K. E., Foor, C. J., and Maness, N. E. 1992. Biological and chemical control of Rhizoctonia aerial blight of rosemary (Rosemarinus officinalis). (Abstr.) Phytopathology 82:497.

6. Conway, K. E., and Kahn, B. A. 1990. Effects of biological control agents on growth of broccoli seedlings, 1987. Biol. Cult. Tests $5: 12$.

7. DeBaggio, T. 1990. Rosemary and its culture. Herb Companion, Dec./Jan. pp. 34-40.

8. Doornik, A. W. 1980. Some factors affecting the parasitic and saprophytic activity of Rhizoctonia solani. Acta Hortic. 109:387-394.

9. Farr, D. F., Bills, G. F., Chamuris, G. P., and
Rossman, A. Y. 1989. Fungi on Plants and Plant Products in the United States. American Phytopathological Society, St. Paul, MN.

10. Fisher, C. G. 1984. Fluid drilling: A potential delivery system for Trichoderma spp. as biocontrol agents. M.S. thesis. Oklahoma State University, Stillwater.

11. Foster, S. 1986. Herbal Bounty. Gibbs M. Smith, Layton, UT. pp. 136-137.

12. Holcomb, G. E. 1992. Web blight of rosemary caused by Rhizoctonia solani AG-1. Plant Dis. 76:859-860.

13. Kahn, B. A., Conway, K. E., and Fisher, C. G. 1986. Effects of wirestem, wind injury, and iprodione on yields of six broccoli cultivars. HortScience 21:1136-1139.

14. Lewis, J .A., Lumsden, R. D., Papavizas, G. C. and Kantzes, J. G. 1983. Integrated control of snap bean diseases caused by Pythium spp. and Rhizoctonia solani. Plant Dis. 67:1241-1244.

15. Lewis, J. A., and Papavizas, G. C. 1980 Integrated control of Rhizoctonia fruit rot of cucumber. Phytopathology 70:85-89.

16. Lifshitz, R., Lifshitz, S., and Baker, R. 1985. Decrease incidence of Rhizoctonia preemergence damping-off by use of integrated chemical and biological controls. Plant Dis. 69:431-434.

17. Maness, N. E., and Motes, J. E. 1991. Propagating rosemary (Rosemarinus officinalis) by cuttings. (Abstr.) HortScience 265:485.

18. Maness, N. E., Motes, J. E., Conway, K. E., and Warde, W. D. 1992. Improving propagation of Rosemarinus officinalis (rosemary) cuttings: Method of hormone application and control of Rhizoctonia solani infection. (Abstr.) HortScience 27:1179.

19. Ogoshi, A. 1975. Grouping of Rhizoctonia solani Kühn and their perfect stages. Rev. Plant Prot. Res. 9:93-103.

20. Papavizas, G. C., Dunn, M. T., Lewis, J. A., and Beagle-Ristano, J. 1984. Liquid fermentation technology for experimental production of biocontrol fungi. Phytopathology 74:11711175 